\title{
IS RELIGION THERAPEUTICALLY SIGNIFICANT FOR HYPERTENSION?
}

\author{
JefFrey S. LeVIN ${ }^{1}$ and HAROLd Y. VANDERPOOL ${ }^{2}$ \\ 'Institute of Gerontology, University of Michigan, 300 North Ingalls, Ann Arbor, MI 48109-2007, U.S.A. \\ and 'Institute for the Medical Humanities, The University of Texas Medical Branch, Galveston, TX 77550, \\ U.S.A.
}

\begin{abstract}
Epidemiologic studies of the effects of religion on blood pressure suggest that religious commitment is inversely associated with blood pressure and that several religious denominations or groups have relatively low rates of hypertension-related morbidity and mortality. In this review, we examine the implication that certain characteristics and functions of religion account for this association, and we posit 12 possible explanations for this finding. We propose that a salutary effect of religion on blood pressure can be explained by some combination of the following correlates or sequelae of religion: the promotion of health-related behavior; hereditary predispositions in particular groups; the healthful psychosocial effects of religious practice; and, the beneficial psychodynamics of belief systems, religious rites, and faith. Since past epidemiologic studies may have been methodologically limited or flawed, possible explanations for the findings of these studies also include epistemological confusion, measurement problems, and analytical errors. Finally, for the sake of completeness, two more speculative hypotheses are identified: superempirical and supernatural influences or pathways.
\end{abstract}

Key words - blood pressure, hypertension, religion, methodology, epidemiology

\section{INTRODUCTION}

Hypertension is a serious and widespread clinical and public health problem. For many people with common, nonsevere forms of high blood pressure, nondrug therapies are often the treatments of choice. Behavioral or psychosocial treatment modalities typically include stress-reduction, dietary change, and various alterations in life style. Because research into the efficacy of these factors has implications for both treatment and primary prevention, social epidemiologists have long shown interest in the effects of these kinds of socioenvironmental and intrapsychic determinants.

In many epidemiologic studies of cardiovascular disease, researchers have included one or more indicators of religious involvement. This is perhaps informed by the assumption that religion or religiosity may represent a reflection or avenue of psychosocial influence and, thus, in some unspecified manner, be therapeutically significant. Indeed, many epidemiologists are aware that significant associations between measures of religion and blood pressure exist in the literature, and many clinicians are aware of anecdotal evidence regarding patients whose high blood pressure was helped or better managed because of some regimen or some system of meditation sanctioned by a religious group. Occasionally, after noting a collection of seemingly anomalous findings involving religion variables, a reviewer will tentatively postulate a therapeutic role for religion. Jenkins' comprehensive overview of psychosocial precursors to heart disease [1] and Kaplan's excellent prolegomenon on the cardiovascular effects of religious beliefs [2] are examples of such reviews. Epidemiologists are typically urged to tread gingerly in such virgin terrain, and to exhibit great caution in drawing any definitive conclusions [3]. These warnings sometimes imply that published data are scant, that existing findings are largely inconsistent, and that greater attention to conceptual and theoretical issues would be premature at the present time. This paper challenges each of these conclusions and offers a new approach that will enable researchers to investigate more precisely how religious factors may be related to cardiovascular disease and hypertension specifically, and health status generally.

The scientific study of the effects of religion on morbidity and mortality was first reviewed by Levin and Schiller [4], who were surprised to discover roughly 250 studies dating back over 150 years which incorporated at least one measure of religion, variously defined. Over four dozen of these studies included analyses of the effects of religion on cardiovascular disease, and many focussed specifically on hypertension. This paper elaborates on the hypertension section of the Levin and Schiller review as augmented by several more recent studies, and represents the first comprehensive overview of empirical research on religious factors in blood pressure.

Many investigators may be surprised to discover that the literature detailing the impact of religion on blood pressure comprises nearly 20 studies published over 30 years. Outcome variables in these studies include mean blood pressure, systolic (SBP) and diastolic (DBP) blood pressure, hypertensive heart disease mortality, hypertension-related mortality, and history of hypertension. Measures of religion include religious attendance, church membership, religious affiliation, ethnic traditions within Judaism, monastic orders, clergy status, religious education, and subjective religiosity. Implicit in these studies is the suggestion that religion may be therapeutically significant for hypertension. This suggestion clearly merits scrutiny, assessment, and synthesis. 
This paper consists of two parts. First, published findings are critically reviewed. Second, 12 hypotheses are posited as alternative explanations for why measures of religion might be significantly associated with blood pressure variables. These hypotheses can serve to generate additional explanatory factors for future research in this area, as well as for other studies examining the effects of religion on morbidity, mortality, and health.

\section{REVIEW OF EMPIRICAL FINDINGS}

Published studies in this area are best reviewed by segregating them on the basis of how they operationalize religion. Implicit in the use of continuous measures of behavior (e.g. religious attendance) or attitudes (e.g. subjective religiosity) is the assumption that religious experience and commitment represent a cluster of investigatable effects-independent variables - that can be related to health outcomes through multivariable analyses. Those studies examining the effects of religious commitment will be considered first. Second, studies that utilize categorical measures of religious affiliation will be reviewed. In this second set of studies, differences in blood pressure variables are examined either by contrasting a religious denomination or group with an all-others category (e.g. Mormons vs non-Mormons; Buddhists vs non-Buddhists) or by contrasting two different religious groups (e.g. Trappists vs Benedictines; Mormons vs Seventh-Day Adventists). Segregating studies into these categories serves a useful heuristic end, for it captures the very different types of analyses employed in the literature.

\section{Religious commitment}

Several studies have investigated the effects of various behavioral and attitudinal indicators of religious commitment on blood pressure. Overall, these studies indicate that subjects reporting higher levels of religious commitment seem to be at lower risk for morbidity and mortality. Findings are summarized in Table 1.

The earliest studies-and some of the most influential in the "epidemiology of religion" [5]were Scotch's seminal investigations of hypertension among Zulus. Using DBP $\geqslant 90$ as a definition of morbidity, and controlling for education and the ability to speak English, Scotch found significant protective effects both for religious attendance among rural subjects and for church membership among urban female subjects [6]. He also collected data on a more subjective religious indicator-bewitchment-and found that urban subjects who believed they had been bewitched were at a significantly increased risk for hypertension [7].

A recent Israeli study also evidenced a protective effect for religion. Among Jewish subjects from Jerusalem, it was determined that females whose fathers had 5 or more years of Yeshiva (Jewish religious education) had significantly lower DBP than those whose fathers had received less instruction [8].

Four recent studies have focussed on the effects of religious attendance. Two of these were multiethnic investigations of immigrants to Ohio. One study found lower SBP and DBP in monthly churchgoers than in less frequent attenders, although the trend fell just short of statistical significance [9]. The other study found a significant, inverse association between religious attendance and biologic effective blood pressure, an algebraic combination of SBP and DBP [10]. In a study in Evans County, Georgia, subjects reporting at least weekly religious attendance had lower SBP, even after controlling for Quetelet score, or body mass [11]. In a study in San Antonio, Levin and Markides [12] found just the opposite. Among older Mexican Americans in a three-generations sample, religious attendance was not significantly associated with a history of hypertension. However, a singleitem measure of subjective religiosity was significant, and in a positive direction. Because this study examined older subjects, however, this latter finding may be spurious when generalized. On the one hand, the least religious subjects in this population may have been excluded from the study because of mortality due to hypertension. On the other hand, the onset of morbidity due to hypertension may have engendered a turn toward greater religious concern. Either circumstance could have produced this unexpected finding [13].

To summarize, all but one of the above studies suggest that certain religious indicators are associated with lower blood pressure or lower rates of hypertension. Five studies revealed protective effects for religion and a sixth showed a strong, but nonsignificant protective trend, while the seventh study's finding of a deleterious effect may have been spurious due to its cross-sectional design.

\section{Religious affiliation}

Additional studies have investigated rates of hypertension morbidity or mortality across religious denominations or groups. In most instances, these studies contrast a delimited religion, denomination, or sect (e.g. Buddhists, Protestants, Mormons) with a more inclusive 'all others' category of subjects. In most of these investigations, the more homogeneous religious group was found to be at significantly lower risk. Findings are summarized in Table 2.

Since the two most comprehensively studied religious groups in epidemiologic research are SeventhDay Adventists and Mormons [4], it is not surprising that they are represented in research on hypertension. In one study, Adventists had significantly lower mean SBP and DBP than non-Adventists [14], and, in another, Adventists were less likely than non-Adventists to have SBP $\geqslant 160$ and/or DBP $\geqslant 95$ [15]. Both studies were from Australia. Similarly, data from Utah showed that Mormon males had a significantly lower rate of hypertensive heart disease mortality than their non-Mormon counterparts [16].

In a study comparing Seventh-Day Adventists and Mormons [17], both male and female Adventists had lower SBP, and the female Adventists had lower DBP, as well. These findings were attributed to the vegetarian diet of most Adventists. Interestingly, two studies of vegetarian and nonvegetarian subjectsTrappist and Benedictine monks, respectivelyobtained results conflicting with the AdventistMormon findings. Similar to Adventists and Mormons, Trappists and Benedictines are isolated, 

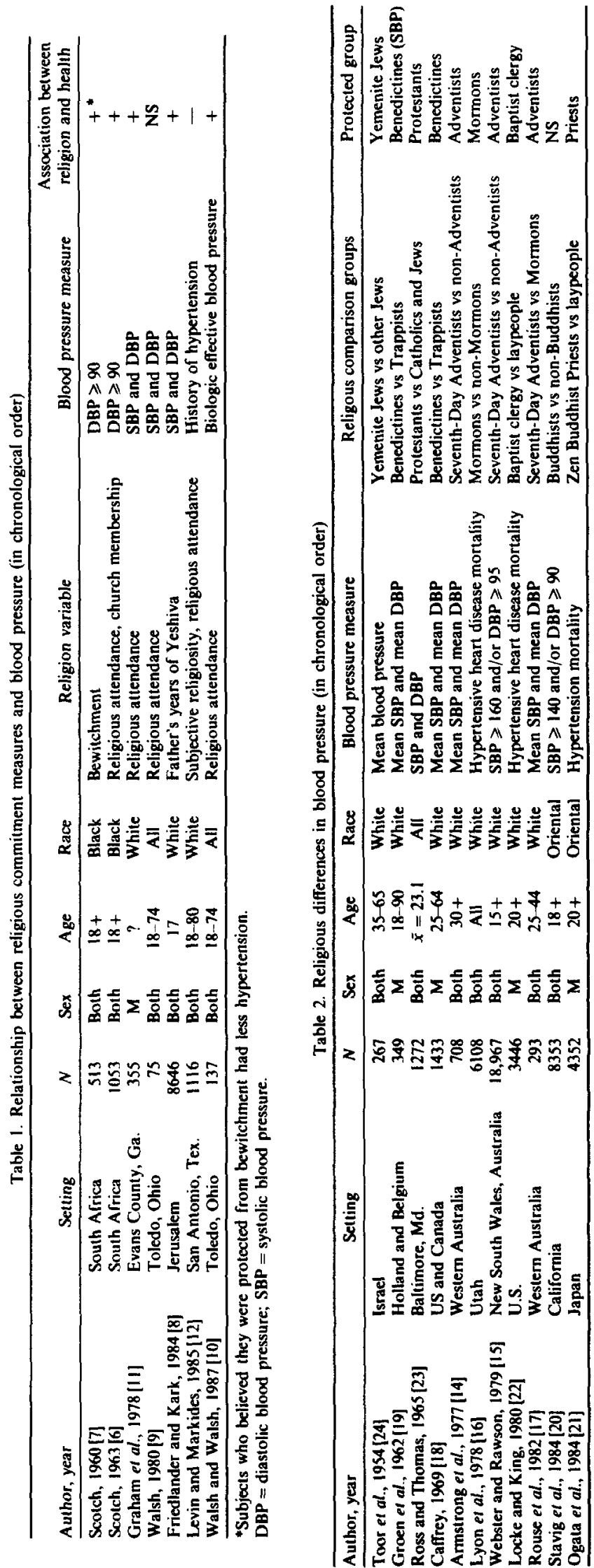
relatively healthy religious groups, yet a comparison of the two monastic orders revealed that the vegetarian subjects (Trappists) had higher mean blood pressure $[18,19]$. These results show that differences in blood pressure among similarly cohesive religious groups may not be reducible to a dietary effect.

Two recently published studies included Buddhist subjects. When Buddhist and non-Buddhist Californians were compared, Buddhists were less likely to have $\mathrm{SBP} \geqslant 140$ and/or $\mathrm{DBP} \geqslant 90$, although this finding fell just short of statistical significance [20]. In a Japanese study, Rinzai Zen Buddhist priests had a significantly lower rate of mortality due to hypertension (standardized mortality ratio $=50$ ) than did lay subjects of miscellaneous religious backgrounds [21].

Another study focussed on blood-pressure differences between clergy and laypeople. As a part of a larger series of investigations of the morbidity and mortality patterns of the clergy, Locke and King [22] found that male clergy of the American Baptist Convention had a significantly lower rate of mortality due to hypertension with heart disease (standardized mortality ratio $=61$ ) than a comparison group of white, U.S., lay men.

Two investigations comparing Christians and Jews also found significant differences in blood pressure. Among female medical students at Johns Hopkins, Protestants had lower SBP and DBP than did nonProtestants (Catholics and Jews). When this analysis was rerun contrasting Jews and Gentiles, Jews were found to be at higher risk [23]. A 35-year-old study from Israel found that Yemenite Jews had lower mean blood pressure than other Jews [24]. Oriental Jews such as Yemenites may be more likely to maintain strict Orthodox traditions than Israeli Jews generally, the majority of whom have Ashkenazi (European) backgrounds. Conclusions about the relationship between blood pressure and the extent of observance are only speculative, however, since no data addressed the degree to which study subjects adhered to Orthodox tradition. The study further indicated that more recent Yemenite immigrants had even lower blood pressure than their more established counterparts. This finding, however, may have been spurious due to an effect of aging, with the earliest immigrants likely being the oldest subjects.

In sum, studies of differences in blood pressure across religious affiliations suggest that adherents to delimited religious groups-especially highly devout, behaviourally strict groups such as Mormons, Scventh-Day Adventists, Buddhists, and the clergyhave significantly lower rates of hypertension-related morbidity and mortality than comparison populations. Coupled with the previous findings on religious commitment, it appears that higher degrees of religious expression or identification may represent a significant protective factor against high blood pressure and hypertension-related morbidity and mortality. We will now offer several possible explanations for this summary finding.

\section{ALTERNATIVE EXPLANATIONS FOR A SALUTARY} RELIGIOUS EFFECT ON BLOOD PRESSURE

Although considerable in number and suggestive of a general trend, these findings nonetheless do not constitute proof of a consistent, salutary effect of religious belief or spiritual forces on blood pressure. This is the case because 'religion' incorporates many variables that frequently are not identified and measured [5]. Beliefs and/or spiritual or supernatural forces or influences. for example, need to be disentangled from various social, psychological, and biological characteristics and functions of religious groups and religious group membership, many of which have been found to influence health. Several of these characteristics and functions are rather mundane, in that while they are characteristic of religious groups, they are not exclusive to these groups or to some particular religious system of belief. Consider, for example, factors respecting social support, dietary regimens, or familial and ethnic genetic inheritance.

Similar to epidemiologic investigations in other substantive areas [5], the above studies of religion and hypertension suffer from two problems: (1) a disparity in measures of the independent construct, in this case religion, and (2) the largely uncontrolled nature of analyses. Any summary finding of a protective effect for religion should thus be considered as suggestive at the present time. Unfortunately, a continued collection of data along the lines of previous research on hypertension is unlikely to clarify matters, for the religious indicators in this literature may in fact represent proxy measures of quite different mechanisms or determinants which are potentially related to blood pressure.

To advance research in this area, a set of specific hypotheses are needed to guide the epidemiologic study of religion. The following 12 hypotheses are offered as alternative explanations and as an initial step for advancing research. First, six biobehavioral or sociomedical explanatory hypotheses are offered as ways to account for significant associations between religious measures and blood pressure. Each of these hypotheses focusses on a different functional or structural component of religion-for example, the sanctioning of certain behavior; genetic predisposition; the provision of fellowship; or the psychodynamic influence of religious belief, expression, or faith. The next three explanations are rooted in methodological problems commonly encountered in this literature. These hypotheses suggest that current findings may be spurious or artifactual for reasons related to errors or flaws in conceptualization, measurement, and/or analysis. A tenth explanation proposes a multifactorial combination of the preceding explanations as the best way to understand significant findings. Finally, and for the sake of completeness, two more speculative hypotheses are included that refer to elements typical of religious language and belief, yet are outside the established bounds of science. These are termed respectfully the superempirical and supernatural hypotheses. The former invokes influences or 'pathways' presently considered nonmeasurable, while the latter proposes effects which are, by definition, transcendent.

Hypothesis 1: Behavior. Specific health-promotive regimens respecting behaviors encompassing diet, hygiene, exercise, smoking, and alcohol consumption are expressly sanctioned by the proscriptions and prescriptions of many religious traditions [25]. For example, the Mosaic code prohibits the consumption 
of tref (nonkosher) products; Mormons are warned against caffeine and alcoholic beverages; SeventhDay Adventists are directed to be vegetarian; monks fast; nuns are celibate; Jews and Muslims require circumcision; Parsis marry late and are strictly monogamous. Each of these religiously-sanctioned behaviors is a component of a larger religious Lebensstil, or style of life, and each of these behaviors is generally promotive of health. Many of these behaviors-for example, those respecting diet, exercise, smoking, and drinking-are linked to lower blood pressure through their mitigation of risk factors. These include the intake of saturated fat, cholesterol, and salt; the consumption of alcohol and protein; and, obesity.

Because these and other behaviors are explicitly sanctioned or commanded by particular religious groups, they cannot, of course, be considered as entirely nonreligious, for to view them as such reduces religion to some other-worldly realm of belief, feeling, or posited reality [5]. Most religious traditions expressly relate beliefs about a transcendent being(s) or realm to this-worldly feelings, institutions, and behaviors. The social-scientific study of religion thereby assumes that even if investigators deny the existence of such a being(s) or realm, the feelings, behaviors, and institutions directly motivated by beliefs regarding the transcendent are inherent in religion.

Having granted that behaviors such as those underlying significant associations between religious belief and blood pressure are religiously motivated, it is nevertheless impossible on empirical grounds to prove that such associations validate religious claims. One cannot prove, for example, that God blesses those who follow behaviors productive of better health and curses those who do not. Although these claims are made unambiguously in religious literature (e.g. Deuteronomy 28:1-68) and are a source of comfort to faithful Seventh-Day Adventists, Mormons, and others, questions related to God as the ultimate source of better health are matters of confession and faith, rather than fact. This is all the more evident when proximate or this-worldly explanations-such as those that follow-are verified scientifically.

Hypothesis 2: Heredity. Because certain religious groups or, more correctly, certain religio-ethnic groups preserve interfamilial patterns of heredity, these groups are predisposed to hypertension and other diseases or to normotension and longer, healthier lives. Biomedical and epidemiologic studies report increased or decreased risks among particular religiously delineated subpopulations for a variety of conditions. Aside from those related to hypertension, findings include higher rates of familial hypercholesterolemia among Dutch Reformed Afrikaaners [26]; higher rates of circulatory diseases, colitis, and TaySachs disease in Ashkenazi Jews [4]; and, lower rates of cancer incidence in Hutterites [27].

While these studies associate specific religious family lineages and ethnic groups with health-related risks, it is questionable that such risks and their ill-effects are inherent to religious belief and motivation-as was the case with behavior in Hypothesis 1 . Within Judaism and Christianity there does exist an ancient belief that divine punishment extends throughout several generations (e.g. Exodus 20:5 and Numbers 14:18), but this deals with punishment for grevious sins that are avenged on several generations of a sinner's ancestors-a view marginally related to happenstance features of genetic disease. Once genetic abnormalities develop, however, strictly enforced taboos against intermarriage can and do perpetuate such abnormalities within the interrelated group. Consider, for example, the likelihood of a higher incidence of sickle cell anemia among the Black constituents of the National Baptist Convention, U.S.A, than in the predominantly white constituency of the Southern Baptist Convention. In such an instance, religious affiliation would constitute a proxy indicator of a certain genotype, rather than reflect denominational differences in beliefs, motivations, feelings, or rituals.

Hypothesis 3: Psychosocial effects. Religious membership and participation give rise to salutary psychosocial outcomes which, in turn, positively influence blood pressure and health. Religion promotes social cohesiveness; engenders a sense of belonging, incorporation, and participation; and sanctions continuity in relationships, family patterns, and other support systems. Through its engendering of fellowship, religion, then, serves as a salutary influence in that it provides social support, which in turn moderates stress and anger and enhances more reflective styles of coping and adaptation. There is evidence that these effects of social support have beneficial effects on health [28, 29], including blood pressure [30]. Perhaps through certain psychoneuroendocrinological pathways, religious experience and fellowship serve to block or inhibit the impact of deleterious emotions such as anxiety and anomie on cardiovascular activity.

Levin and Markides [31] have noted that this explanation for a significant religious effect on health represents "the central, unspoken assumption of epidemiologists working with religion variables" (p. 32). Currently, empirical evidence has not completely validated this hypothesis, because controlling for the effects of social support does not seem to account fully for the significant relationship between religious commitment and health [31]. At any rate, this hypothesis has not yet been explicitly tested with regard to blood pressure.

Hypothesis 4: Psychodynamics of belief systems. The beliefs of particular religious groups give rise to psychodynamics engendering greater peacefulness, self-confidence, and a sense of purpose, or, alternatively, guilt, depression, and self-doubt. Such psychodynamic outcomes may be symbiotic either with personality styles such as Type A (which seems to have deleterious cardiovascular effects) or Type B (which may be associated with hypertension among the unchurched or irreligious [32]), or with certain theological systems of thought such as Calvinist (deterministic) or Wesleyan (free-will) views of human nature. These latter two belief-orientations appear to be conceptually consonant with the respective external and internal components of the locus of control construct [33], which has been associated with health-related behavior [34]. Other belief systems have been shown to liberate or release persons from 
restrictive social and emotional circumstances characterized by anger, hostility, loneliness, and depression. In their place, religious belief characteristically accents self-confidence, steadiness, self-control, and a sense of purpose. Documented examples of these effects include the experiences of lower-caste Hindus who have converted to Buddhism [35] and black Americans who joined the Black Nation of Islam during the heyday of the late Elijah Muhammad [36].

Hypothesis 5: Psychodynamics of religious rites. The experiences of religious persons through public and private rituals serve to ease dread and anxiety, reduce personal and group tension and aggressiveness, allay fears, and moderate loneliness, depression, anomie, and/or feelings of entrapment and inferiority [35]. Many of these negative affects may be determinants or sequelae of elevated blood pressure [37]. Characteristically, religious rites utilize suggestion, confession, and various group processes (such as emotional arousal, followed by enactments of negative feelings, and then emotional reintegration) to instill peace and a greater sense of self-direction and mastery [38-41]. These rites-through which persons dramatize or act out their beliefs in settings conducive to or charged with emotion-provide avenues of escape, purification, catharsis, and empowerment. These positive affects may serve as sorts of psychic beta-blockers or emotional placebos which mitigate the body's attempt to elevate blood pressure. Rituals from pre-modern, Western, and Eastern traditions encompass mental and physical healing rites or procedures which are associated ethnographically with such cardiovascular-related responses [42].

Hypothesis 6: Psychodynamics of faith. Whether or not patterns of religious belief (Hypothesis 4) or practice (Hypothesis 5) are stabilizing and generally health-promotive, the religious persons's faith that they are may contribute to better health. The work of the Simontons [43] on the role of beliefs in changing the course of malignancy, coupled with findings on placebo effects [44], suggest that certainty and anticipation that beliefs or practices will bring rewards may by itself effect healing. Such affects may have a bearing on hypertension and normotension. Words like those of the Prophet Isaiah-" "no weapon that is formed against thee shall prosper" (Isaiah 54:17 [KJV]) - may serve to fortify the faithful and, through stimulating certain hormonal responses, contribute to the prevention or cure of certain maladies. This may explain numerous 'miraculous' and/or spontaneous cures-especially in highly suggestible persons. An acceptance of the validity of such psychosomatic processes seems to have passed into the popular domain, where many persons tacitly accept some form of mind-body interaction, despite the fact that some physicians remain skeptical or resistant to nonbiological etiologies [45]. Belief in the therapeutic value of faith and positive thinking is directly and indirectly informed by a long-standing legacy of mind-(and spirit-)over-matter thought in America $[46,47]$.

Hypothesis 7: Epistemological confusion. Unidimensional religious indicators are typically assumed to represent valid measures that lend themselves to cross-group comparisons, when, in fact, such indicators may mask diverse meanings and tap divergent constructs. Consider, for example, religious attendance. A measure of the frequency of attendance may in part tap the provision of social support, the experience of the catharsis of ritual, and/or the calming effects of prayer and meditation. As the above hypotheses suggest, these may be inversely related to blood pressure and positively related to health (as would appear to be the case for many charismatics or members of Pentecostal denominations). Other groups (Catholics? members of the Churches of Christ?) may encompass larger percentages of subjects who attend services out of obligation, guilt, and/or fear. For many such congregants, more frequent religious attendance could result in higher blood pressure and poorer health outcomes [2]. Alternatively, many believers may attend services more often because they are already ill and are seeking divine healing. The uninformed operationalizing of religious constructs can thus lead to confused and inaccurate conclusions. Epidemiologists and other sociomedical researchers can avoid such conclusions by working with specialists (e.g. psychologists of religion, sociologists of religion, and other experts in quantitative religious studies) experienced in measuring rcligious phenomena [5].

Hypothesis 8: Measurement problems. Researchers often assume that a particular religion variable represents a uniform and therefore meaningful measure, when in fact problems of validity may be inherently present. Consider again the case of religious attendance. The most commonly used indicator of religiousness found in the epidemiologic and medical literature is the frequency of religious attendance. This is usually ascertained by a single, continuous item such as, 'On the average, how often would you say you attend religious services?' The problem here is that responses to this item mean or imply different things to different religious groups, some of which expect far more frequent attendance in observant members than do other groups [5]. This calls for careful attention to the meaning of religious attendance within respective denominations.

Furthermore, an indicator of religious attendance may also mean different things for different subgroups within a single religious group. For example, among older congregants whose health is in decline, a religious attendance variable may capture the effects of functional health (i.e. the absence of disability or activity limitation). For these older people, a significant inverse association between religious attendance and blood pressure or health may only mean that healthy, normotensive people are healthy enough to climb out of bed and go to church or synogogue. Thus, while religious attendance indeed appears to predict normotension and health, it may be false for purposes of explanation to assume that a religious attendance item always captures the effects of religious commitment or some intrinsic sense of religiosity.

Hypothesis 9: Analytical errors. In light of such measurement problems, significant associations between blood pressure and particular religion variables, most notably religious attendance, may be spurious because the observed relationship is confounded by 'hidden' (and thus uncontrolled) factors, such as self-ratings of global or functional health. A 
recent series of papers by Levin and associates $[5,12,13,31,48,49]$ has shown that controlling for activity limitation often reduces the magnitude of associations between religious attendance and morbidity or poor health. Without collecting such data on functional health status or disability and then adjusting for these effects, significant associations between religious attendance and blood pressure may be spurious or tautological. That is, these associations may represent de facto correlations between lack of disabling morbidity and health, or, in other words, between health and health.

In addition to functional health, consider two other common epidemiologic correlates, social class and age. With respect to social class, imagine that a study indicates that American Jews are found to be at lower risk than American Gentiles with respect to a deleterious health-status outcome. Before one can assume that this study offers proof, for example, that a Jewish milieu or ethos is somehow conducive to better health (in keeping with Hypotheses 3-6), social-class effects must first be considered. Since sociological studies have typically found that, on average, American Jews tend to have somewhat higher levels of education and income than Gentiles, and since education and income are strong predictors of health, Jewish norms of socioeconomic status might account for their better status on the health outcome under study. Were these effects to be controlled, the hypothetical Jewish advantage might disappear. If so, then speculation over Hypotheses 1-6 above would be unwarranted. At the same time, however, interplays between religious background and social class might prove to be interestingly related to health.

With respect to age, consider the papers reviewed earlier $[18,19]$, in which vegetarian Trappist monks had unexpectedly higher mean blood pressure than their omnivorous Benedictine counterparts. Although several dietary, intrapsychic, or theological explanations could be postulated to explain this finding, the most plausible one is that, despite their vegetarianism, Trappist subjects had higher blood pressure because they constituted an older sampleas indicated in these papers' descriptive findings. Since epidemiologic studies suggest that blood pressure tends to rise with age, such a result is not surprising. These are just two examples of the dangers of uncontrolled analyses. Hasty and incorrect conclusions are best prevented by formulating careful theoretical models and then doing them justice by avoiding low-order (i.e. poorly controlled) analyses.

Hypothesis 10: Multifactorial explanation. A nonreductionistic combination of some or all of the above explanations best describes the relationship between religion and blood pressure. Theoretically, given the several components of religion [5], it would appear that no one explanation can explain why certain expressions or characteristics of religion seem to promote cardiovascular health. This complexity likely manifests itself statistically: the operational features and physiological effects of no one particular explanation (e.g. diet, genes, social support, locus of control, personal adjustment, faith) can completely account for a given significant association between indicators of religion and blood pressure.
Consider as an example the data regarding Seventh-Day Adventists' relatively lower rates of hypertension-related morbidity and mortality. It is difficult to prove that this advantage is entirely explained by the beneficial effects of one of the distinctive characteristics of this denomination-its members' vegetarianism. Rather, Adventists may have lower blood pressure and less hypertension because their characteristic religiosity engenders a composite of beliefs, feelings, and behaviors promotive of cardiovascular health. To refer to Hypotheses 1-6, respectively, this might include the avoidance of meat (leading to low levels of dietary fat and cholesterol); the discouragement of intermarriage (supporting a trend toward selecting out of the population those persons predisposed to hypertension); an emphasis on family solidarity and religious fellowship (buffering the adverse physiological consequences of life stress and anxiety); a theological emphasis on self-responsibility and positive health-directedness (encouraging self-care and beneficial health-related behavior); a sense of trust and peace engendered both through expectations of God's directly transforming the world and through ritual experience of transformation through divine power (preventing or ameliorating state anxicty, hassles and uplifts, anger, etc.); and, a sense of purpose and well-being because the worldview and piety of Adventists is believed to be promotive of health (reinforced by the relative lack of hypertension-related morbidity among co-religionists).

Hypothesis 11: Superempirical infuence(s). A pantheistic or superempirical force is tapped by or inherent in religious practices, beliefs, and rituals. This accessible, although presently immeasurable and ineffable healing force or energy is attributed many names across various religious and mystical traditions: ether, prana, life force, wakan, Holy Spirit, kundalini energy, Christ Consciousness, chi or ki, eloptic energy, baraka, orgone, ruakh, fohatic power, huna, odic force, mana, second state energy, Gestaltung, the mytogenetic ray, munia, the It, Odyle, and so on $[50,51]$. While most religious traditions forbid, discourage, or place restrictions on delving into the mysteries of such power(s), others seek to discover and unleash it through occult experimentation, meditation (either as therapy or self-actualization), the recreational or therapeutic use of hallucinogens, or initiation into the mysteries of some school or group.

Lest such a force be viewed as hopelessly foreign and mystical, readers should note that salutary effects on blood pressure have been identified for various techniques that claim to draw their power from such a superempirical force. These include the practice of hatha yoga-a combination of certain asanas (postures) and pranayama (breathing) exercises [52]; outof-body journeys to some higher plane [53]; the use of healing devices constructed from crystals [54]; the therapeutic application of green light to stimulate the proper functioning of the heart chakra [55]; the repetition of certain affirmations obtained through 'channelling' ("I joyously release the past. I am at peace.") in order to create new thought patterns and eliminate longstanding emotional problems [56]; the utilization of healers who, under the guidance of disembodied 'masters', empower adherents with fresh energy that releases or unblocks their resistance to 
such energy [57]; and, the use of 'radionic' devices to correct imbalances in the flow of life energy throughout the body [58]. Numerous paths to normotension and health-some even stranger than these [59]-are found in the literatures of mysticism and unorthodox science.

Many scientists, physicians, and clergy thinking and working from within contemporary scientific paradigms will naturally view these types of forces with grave skepticism, if not outright derision [60]. However, given (a) the studies referenced above, (b) the possibility that in the future such forces will be identified and measured [61], (c) recent accounts that offer preliminary evidence of measuring such subtle influences $[58,62,63]$, and (d) longstanding belief in them within religious traditions, the existence of such forces should not be dismissed out of hand and without investigation. Even if such subtle and presently mystifying influences are identified in the future, their significance as a factor impacting on human health would nevertheless have to be weighed against the several factors identified in the other hypotheses outlined above.

Hypothesis 12: Supernatural influence(s). An active power that transcends or exists independently of the natural world chooses when and why to bless or endow individuals or groups of persons with normotension and lower rates of hypertension-related mortality-or with better health generally. An understanding of the world with this view of divine power is accented within traditional Judaism, Christianity, and Islam. These traditions uphold the transcendence of God, while at the same time not necessarily denying divine immanence-that is, the power and presence of God within nature and history. Generally, the more orthodox branches of these major religious heritages hold that God exists both within and beyond the natural world, thus opposing both absolute transcendence and complete immanence (i.e. pantheism). This means that, on theoretical grounds, Jews, Christians, and Muslims can agree with Hypothesis 11 without denying the possibility of nonmeasurable, nonquantifiable supernatural intervention, blessing, or grace in matters of human health. It nevertheless follows that insofar as divine power transcends natural laws, it cannot be the subject of scientific scrutiny and experimentation.

\section{SUMMARY}

On the basis of this review, the question, 'Is religion therapeutically significant for hypertension?', is best answered with a qualified, 'probably'. The nearly 20 empirical studies reviewed here suggest that characteristics and functions of religion have salutary effects on blood pressure.

We have shown, however, that these studies' samples, religious indicators, and even blood pressure measures are far from comparable and that most analyses were either of low order or uncontrolled. Furthermore, many of these studies did not investigate religious effects directly. That is, typically (and uncritically), their respective religion variable was considered as just one of numerous psychosocial or behavioral constructs. By design, their data collection instruments were thus often unable to assess those other factors (outlined in the above hypotheses) which might bear specifically on the relationship between religion and blood pressure. Although this point raises caution with respect to the conclusions of these studies, it also warns us against hypercriticism, for it was not the primary intent of these studies to examine religious influence per se. Nevertheless, the lack of specificity of existing studies warrants a new research agenda. Precisely because prior studies suggest that religious factors may be significant within a multifactorial framework, such studics invite and legitimate an exploration of more specific and targeted explanations for religious influence on blood pressure.

In order to facilitate this exploration, we have delineated 12 separate theoretical bases for testing whether and/or how religion variables may be significantly associated with blood pressure specifically, and health generally. Coupled with the salutary summary effect of religion on blood pressure as suggested by the literature, the competing hypotheses enumerated here can serve as the basis for more direct investigation in the future, founded, it is hoped, on more carefully delineated theoretical models [e.g. $64,65]$. Because religious practice pervades human society and because hypertension is a common and serious problem which appears to be mitigated by religion, the question of whether characteristics or functions of religion can indeed lower or prevent high blood pressure is both scientifically and clinically intriguing. Since decades of research have identified numerous hereditary, behavioral, psychosocial, psychodynamic, stress-related, and psychosomatic correlates and predictors of hypertension, and since religion functions and expresses itself through each of these factors, if salutary religious effects are to be found anywhere, they should appear here.

Acknowledgements - The authors wish to thank John $M$. Wallace and C. David Jenkins, as well as two anonymous referees, for their helpful comments on previous drafts of this manuscript.

\section{REFERENCES}

1. Jenkins C. D. Psychological and social precursors of coronary disease. New Engl. J. Med. 284, 244-255, 307-317, 1971.

2. Kaplan B. H. A note on religious beliefs and coronary heart disease. J. S. Car. Med. Ass. Suppl. 60-64, February 1976

3. Hinkle L. E. Social factors and coronary heart disease. Soc. Sci. Med. 2, 107-110, 1968.

4. Levin J. S. and Schiller P. L. Is there a religious factor in health? J. Religion Hith 26, 9-36, 1987.

5. Levin J. S. and Vanderpool H. Y. Is frequent religious attendance really conducive to better health? toward an epidemiology of religion. Soc. Sci. Med. 24, 589-600, 1987.

6. Scotch N. A. Sociocultural factors in the epidemiology of Zulu hypertension. Am. J. publ. Hlth 53, 1205-1213, 1963.

7. Scotch N. A. A preliminary report on the relation of sociocultural factors to hypertension among the Zulu. Ann. N.Y. Acad. Sci. 84, 1000-1009, 1960.

8. Friedlander Y. and Kark J. D. Familial aggregation of blood pressure in a Jewish population sample in Jerusalem among ethnic and religious groupings. Soc. Biol. 31, 75-90, 1984. 
9. Walsh A. The prophylactic effect of religion on blood pressure levels among a sample of immigrants. Soc. Sci. Med. 14B, 59-63, 1980.

10. Walsh A. and Walsh P. A. Social support, assimilation, and biological effective blood pressure levels. Int. Migration Rev. 21, 577-591, 1987.

11. Graham T. W., Kaplan B. H., Cornoni-Huntley J. C., James S. A., Becker C., Hames C. G. and Heyden S. Frequency of church attendance and blood pressure elevation. J. behav. Med. 1, 37-43, 1978.

12. Levin J. S. and Markidase K. S. Religion and health in Mexican Americans. J. Religion Hlth 24, 60-69, 1985.

13. Levin J. S. Religious factors in aging, adjustment, and health: a theoretical overview. J. Religion Aging. 4(3/4), $133146,1989$.

14. Amstrong B., Van Merwyk A. J. and Coates H. Blood pressure in Seventh-Day Adventist vegetarians. Am. J. Epidem. 105, 444-449, 1977.

15. Webster I. W. and Rawson G. K. Health status of Seventh-Day Adventists. Med.J. Aust. 1, 417-420, 1979.

16. Lyon J. L., Wetzler H. P., Gardner, J. W., Klauber M. R. and Williams R. R. Cardiovascular mortality in Mormons and non-Mormons in Utah, 1969-71. Am.J. Epidem. 108, 357-366, 1978.

17. Rouse I. L., Armstrong B. K. and Beilin L. J. Vegetarian diet, lifestyle and blood pressure in two religious populations. Clin. exp. Pharmac. Phys. 9, 327-330, 1982.

18. Caffrey B. Behavior patterns and personality characteristics related to prevalence rates of coronary heart disease in American monks. J. chron. Dis. 22, 93-103, 1969.

19. Groen J. J., Tijong K. B., Koster M., Willebrands A. F., Verdonck $G$. and Pierloot $M$. The influence of nutrition and ways of life on blood cholesterol and the prevalence of hypertension and coronary heart disease among Trappist and Benedictine monks. Am. J. clin. Nutr. 10 , 456-470, 1962.

20. Stavig G. R., Igra A. and Leonard A. R. Hypertension among Asians and Pacific Islanders in California. Am J. Epidem. 119, 677-691, 1984.

21. Ogata M., Ikeda $M$. and Kuratsune $M$. Mortality among Japanese Zen priests. J. Epidem. commun. Hith 38, 161-166, 1984.

22. Locke F. B. and King H. Mortality among Baptist clergymen. J. chron. Dis. 33, 581-590, 1980.

23. Ross D. C. and Thomas C. B. Precursors of hypertension and coronary disease among healthy medical students: discriminant function analysis. III. Using ethnic origin as the criterion, with observations on parental hypertension and coronary disease and on religion. Bull. Johns Hopkins Hosp. 117, 37-57, 1965.

24. Toor M., Agmon J. and Aallalouf D. Changes of serum total lipids, total cholesterol and lipid-phosphorous in Jewish Yemenite immigrants after 20 years in Israel. Bull. Res. Council Israel 4, 202-203, 1954.

25. Spector, R. E. Cultural Diversity in Health and Illness. Appleton-Century-Crofts, New York, 1979.

26. Torrington M. and Botha J. L. Familial hypercholesterolaemia and church affiliation. Lancet 2, 1120, 1981.

27. Morgan K., Holmes T. M., Grace M., Kemel S. and Robson D. Patterns of cancer in geographic and endogamous subdivisions of the Hutterite Brethren of Canada. Am. J. phys. Anthrop. 62, 3-10, 1983.

28. Kaplan B. H., Cassel J. C. and Gore S. Social support and health. Med. Care Suppl. 15, 47-58, 1977.

29. Broadhead W. E., Kaplan B. H., James S. A., Wagner E. H., Schoenbach V. J., Grimson R., Heyden S., Tibblin G. and Gehlbach S. H. The epidemiologic evidence for a relationship between social support and health. Am. $J$. Epidem. 117, 521-537, 1983.

30. Harburg E., Blakelock E. H. and Roeper P. J. Resentful and reflective coping with arbitrary authority and blood pressure: Detroit. Pyschosom. Med. 41, 189-201, 1979

31. Levin J. S. and Markides K. S. Religious attendance and subjective health. J. Sci. Study Religion 25, 31-40, 1986.

32. Levin J. S., Jenkins C. D. and Rose R. M. Religion, Type A behavior, and health. J. Religion Hlih. 27, 267-278, 1988.

33. Levin J. S. and Schiller P. L. Religion and the Multidimensional Health Locus of Control scales. Psychol. Rep. 59, 26, 1986.

34. Wallston B. S. and Wallston K. A. Locus of control and hcalth: a review of the literature. Helth Educ. Monogr. 6, 107-117, 1978

35. Yinger J. M. The Scientific Study of Religion. Macmillan, London, 1970.

36. Lincoln C. E. The Black Muslims in America, revised edn. Beacon Press, Boston, Mass., 1973.

37. Scotch N. A. and Geiger H. J. The epidemiology of essential hypertension. II: psychological and sociocultural factors in etiology. J. chron. Dis. 16, 1183-1213, 1963.

38. Kiev A. The study of folk psychiatry. In Magic, Faith, and Healing (Edited by Kiev A.), pp. 3-15. The Free Press, New York, 1964

39. La Barre W. Confession as cathartic therapy in American Indian tribes. In Magic, Faith, and Healing (Edited by Kiev A.), pp. 36-49. The Free Press, New York, 1964.

40. Turner V. W. An Ndembu doctor in practice. In Magic, Faith and Healing (Edited by Kiev A.), pp. 230-262. The Free Press, New York, 1964.

41. Kaplan B. and Johnson D. The source of meaning of Navaho psychopathology and psychotherapy. In Magic, Faith, and Healing (Edited by Kiev A.), pp. 203-229. The Free Press, New York. 1964

42. Janzen J. M. The Quest for Therapy: Medical Pluralism in Lower Zaire. University of California Press, Berkeley, Calif., 1978.

43. Simonton O. C. and Matthews-Simonton S. Belief systems and management of the emotional aspects of malignancy. J. Transpers. Psychol. 7, 29-47, 1975.

44. White L., Tursky B. and Schwartz G. E. (Eds) Placebo: Theory, Research, and Mechanisms. Guilford Press, New York, 1985.

45. Angell $\mathrm{M}$. Disease as a reflection of the psyche. New Engl. J. Med. 312, 1570-1572, 1985.

46. Ahlstrom S. E. A Religious History of the American People, pp. 1019-1036. Yale University Press, New Haven, Conn. 1972

47. Harrell D. E. All Things are Possible. Indiana University Press, Bloomington, Ind., 1975

48. Markides K. S., Levin J. S. and Ray L. A. Religion, aging, and life satisfaction: an eight-year, threewave longitudinal study. The Gerontologist 27, 660-665, 1987.

49. Levin J. S. and Markides K. S. Religious attendance and psychological well-being in middle-aged and older Mexican Americans. Sociol. Anal. 49, 66-72, 1988.

50. Ludzia L. F. Life Force: The Secret of Empowerment. Llewellyn Publications, St Paul, Minn., 1987.

51. Wilson R. A. Wilhelm Reich in Hell. Falcon Press, Phoenix, Ariz., 1987.

52. Funderburk J. F. Science Studies Yoga: A Review of Physiological Data, pp. 33-41. Himalayan International Institute of Yoga Science \& Philosophy of U.S.A., Honesdale, Penn., 1977.

53. Rogo D. S. Leaving the Body: The Complete Guide to Astral Projection, p. 101. Prentice-Hall, Englewood Cliffs, N.J., 1983.

54. Snider J. and Daab R. The advocacy of Marcel Vogel. Magical Blend 2, 20-26, 1985.

55. Hunt R. The Seven Keys to Color Healing: Diagnosis and Treatment Using Color, pp. 73-75. Harper \& Row, San Francisco, Calif., 1971. 
56. Hay L. L. Heal Your Body: The Mental Causes for Physical Illness and the Metaphysical Way to Overcome Them, revised edn, p. 11. Hay House, Santa Monica, Calif., 1984.

57. Montgomery R. Born to Heal. Fawcett Crest, New York, 1973.

58. Tansley D. V. Chakra-Rays and Radionics, p. 141. Daniel, Saffron Walden, 1984.

59. Levin J. S. and Coreil J. 'New Age' healing in the U.S. Soc. Sci. Med. 23, 889-897, 1986

60. Kurtz P. (Ed.) A Skeptic's Handbook of Parapsychology. Prometheus Books, Buffalo, N.Y., 1985.

61. Wilson R. A. The New Inquisition: Irrational Rationalism and the Citadel of Science. Falcon Press, Phoenix, Ariz., 1986.
62. Rindge J. P. The use of non-human sensors. In Healers and the Healing Process (Edited by Meek G. W.), pp. 130-146. Theosophical, Wheaton, Ill. 1977.

63. Motoyama H. Physiological measurements and new instrumentation. In Healers and the Healing Process (Edited by Meek G. W.), pp. 147-155. Theosophical, Wheaton, Ill., 1977.

64. Jarvis $G$. $K$. and Northcutt $H$. C. Religion and differences in morbidity and mortality. Soc. Sci. Med. 25, 813-824, 1987.

65. Schiller P. L. and Levin J. S. Is there a religious factor in health care utilization?: a review. Soc. Sci. Med. 27, $1369-1379,1988$ 